\title{
Cell Death in Stroke: Role of Metabolism
}

\author{
Saxena $T^{*} *$, Khichi $\mathbf{G}^{2}$ and Saxena $M^{3}$ \\ ${ }^{1}$ Department of Internal Medicine, Mittal Hospital and \\ Research Centre, India \\ ${ }^{2}$ Department of Radio Diagnosis, Mittal Hospital and \\ Research Centre, India \\ ${ }^{3}$ Department Yoga and Physical Education, Mittal \\ Hospital and Research Centre, India \\ *Correspondling author: Tarun Saxena, Department \\ of Internal Medicine, Mittal Hospital and Research \\ Centre, India
}

Received: April 19, 2017; Accepted: May 15, 2017; Published: May 29, 2017

\begin{abstract}
Background: Stroke is one of the major causes of mortality and morbidity. Un-availability of oxygen due to acute reduction in blood flow is the prime reason for stroke. Despite extensive work-up $40 \%$ cases of stroke remain unexplained. The role of metabolism in stroke remains unidentified. Could metabolism play a role in cellular death in stroke? This was the main focus of the study.
\end{abstract}

Methods: This is a descriptive study done retrospectively, through data collection in intensive care and emergency unit of Mittal Hospital Ajmer, India. Arbitrarily record of 200 cases admitted between July 2016 and January 2017 was observed. The data examined was clinical profile, vital parameters, Echocardiography, Magnetic resonance imaging (MRI) and MRI angiography, Carotid Doppler study and Sympathetic skin response (SSR).

Results: MRI suggestive of infarct, maximum in MCA (middle cerebral artery) territory $50 \%$ cases had abnormal MRI angiography, $40 \%$ had abnormal Carotid Doppler study.

Conclusions: In almost a $40-50 \%$ of cases no obstruction in cerebral blood flow/oxygen supply was found. After entering into cells oxygen takes part in aerobic respiration to generate ATP (Adenosine tri phosphate). Therefore it is presumed that in the presence of normal oxygen supply some defect in ATP generation at cellular level is present. This may occur when there is a sudden change in demand of ATP secondary to sudden change in BMR, and cells are unable to generate ATP at a new speed, leading to cell death.

Keywords: Stroke; Cell death; Metabolism; Aerobic respiration; Adenosine tri phosphate (ATP)

\section{Introduction}

Worldwide, the incidences of stroke are on a rise [1-4]. Prevention of cell death remains important in stroke. Reduction in blood flow due to critical narrowing (atherosclerosis) or acute thrombo-embolic occlusion leads to unavailability of oxygen and produces cell death in brain [5-7]. This is the primary reason; however, despite complete evaluation reasons for cell death are not understood in 30-40 percent of cases [8]. Similarly, it is unclear how atherosclerotic narrowing developed over years becomes critical in a few minutes. Is there a sudden increase in oxygen or ATP (Adenosine tri phosphate) demand? Are there other factors that affect cell death? The role of metabolism in cell death in stroke remains unclear. A few studies have suggested inhibition of oxidative metabolism [9-10] that leads to cell death. Still, a clear relationship between metabolism and stroke is yet not decided. Therefore, this study was planned to find any correlation between metabolism and stroke.

\section{Methods}

This is a descriptive study done in a retrospective manner based on data collection through Emergency department and Intensive care unit of Mittal hospital and research centre, Pushkar road Ajmer. The hospital is in Ajmer (a city situated in the central part of Rajasthan, India). Arbitrarily record of 200 cases admitted between July 2016 and January 2017 was observed. The following parameters were examined

1. Clinical profile at 0 hour (admission time) and 48 hours
2. Past history of hypertension/diabetes/stroke/cardiac event

3. Vital parameters including pulse rate, blood pressure, temperature, oxygen saturation (Spo2) at the time of admission

4. Blood investigations including sodium, potassium, calcium, blood glucose, urea, creatinine, Lipid profile

5. Electrocardiogram, Echocardiography

6. Magnetic resonance imaging (MRI), MRI angiography/Carotid Doppler study

7. Sympathetic Skin response (SSR)

\section{Results}

ACA - anterior cerebral artery

MCA- middle cerebral artery

PCA - posterior cerebral artery

Abnormal MRI angiography- Reduced or absent flow due to presence of thrombus/hypoplasia.

Abnormal Carotid Doppler- significant (>70\%) narrowing/ presence of unstable plaque.

TIA- Transient ischemic attack

$50 \%$ of cases of acute stroke had abnormal MRI angiography. $40 \%$ 
Table 1: General examination.

\begin{tabular}{|c|c|c|c|c|c|c|c|c|c|}
\hline $\begin{array}{l}\text { Mean } \\
\text { Age }\end{array}$ & Sex & $\begin{array}{l}\text { Mean pulse ratel } \\
\text { minute }\end{array}$ & $\begin{array}{c}\text { Mean blood } \\
\text { pressure } \mathrm{mm} \mathrm{Hg} \\
(0 \text { hour })\end{array}$ & $\begin{array}{c}\text { Mean blood } \\
\text { pressure mm Hg } \\
\text { (last } 12 \text { months) }\end{array}$ & Smoker & Diabetes & Dyslipidemia & $\begin{array}{l}\text { Spo2 (oxygen } \\
\text { saturation) }\end{array}$ & $\begin{array}{l}\text { History of } \\
\text { TIA }\end{array}$ \\
\hline $\begin{array}{l}50-75 \\
\text { years }\end{array}$ & $\begin{array}{c}65 \% \text { male } \\
35 \% \\
\text { Female }\end{array}$ & $80 \pm 4$ & $160 / 90$ in $40 \%$ & $156 / 90$ in $40 \%$ & $15 \%$ & $55 \%$ & $30 \%$ & $96-99 \%$ & $7 \%$ \\
\hline
\end{tabular}

Table 2: Special investigations.

\begin{tabular}{|c|c|c|c|c|c|c|}
\hline MRI Brain(infarct) & MRI Angiography & $\begin{array}{l}\text { Carotid } \\
\text { Doppler }\end{array}$ & $\begin{array}{c}\text { Carotid } \\
\text { Doppler(intima media } \\
\text { thickness }>0.9 \mathrm{~mm}\end{array}$ & $\begin{array}{c}\text { Electro- } \\
\text { Cardiography }\end{array}$ & $\begin{array}{c}\text { Echo- } \\
\text { Cardiography }\end{array}$ & $\begin{array}{l}\text { Sympathetic Skin } \\
\text { response }\end{array}$ \\
\hline $15 \%$ ACA & Abnormal $50 \%$ & $\begin{array}{c}\text { Abnormal } \\
40 \%\end{array}$ & $20 \%$ & $\begin{array}{l}\text { Rhythm disturbance- } \\
\text { none }\end{array}$ & RWMA 10\% & Huge spikes $85 \%$ \\
\hline $50 \% \mathrm{MCA}$ & Normal $50 \%$ & Normal $60 \%$ & & & Thrombus $2 \%$ & \\
\hline \multicolumn{7}{|l|}{$10 \% \mathrm{PCA}$} \\
\hline $\begin{array}{l}25 \% \text { Vertebro- } \\
\text { basilar }\end{array}$ & & & & & & \\
\hline
\end{tabular}

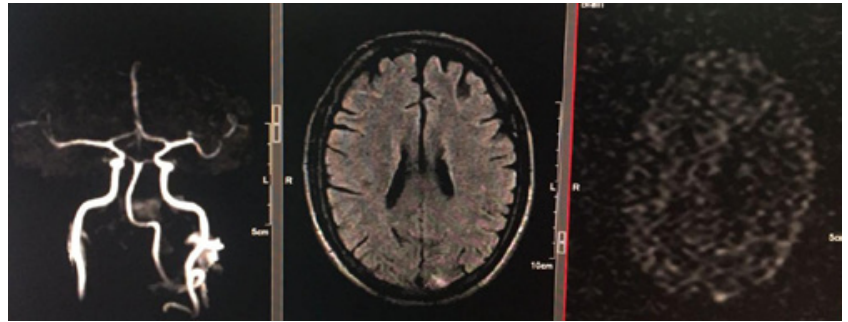

Figure 1: MRI angiography, MRI Flair and MRI diffusion image.

cases had abnormal Carotid Doppler study.

\section{Discussion}

Worldwide, the incidences of stroke are on a rise. Reduction in blood flow produces infarction/ischemia/penumbra zone depending upon severity of unavailability of oxygen in 50\%-55\% of cases. Despite extensive evaluation etio-pathogenesis of 30\%-40\% of cases of stroke remains unexplained [8]. Preservation of cell tissue in stroke remains important. The role of metabolism in cell death in stroke remains dubious. A few studies have depicted the role of inhibition of oxidative metabolism in cell death. Still a clear relationship between metabolism and stroke is not documented. Therefore, this study was planned to observe any correlation between metabolism and stroke.

The study was done in a descriptive, retrospective manner through data collection in Mittal Hospital and Research Centre, Pushkar road Ajmer, Rajasthan, India. Hospital record of 200 cases admitted between July 2016 and January 2017 were observed.

The age group of cases was $50-75$ years. 65 percent were males and 35 percent were females (Table 1).

Initially, we look at the findings of three different cases. In case 1 (Figure 1) there is normal left vertebral, basilar and normal bilateral posterior cerebral arteries, right vertebral is hypoplastic. There is left occipital lobe infarct. In case 2 (Figure 2), there is large right middle cerebral artery (MCA) infarct despite, normal Carotid Doppler study and normal MRI angiography including right MCA. In case 3(Figure 3) there is critical narrowing in cervical part of left internal Carotid artery (ICA), patient coming for routine check- up, clinically normal . Therefore, there is a mismatch, i.e. one to one relationship (i.e. compromise- infarct) is not present.

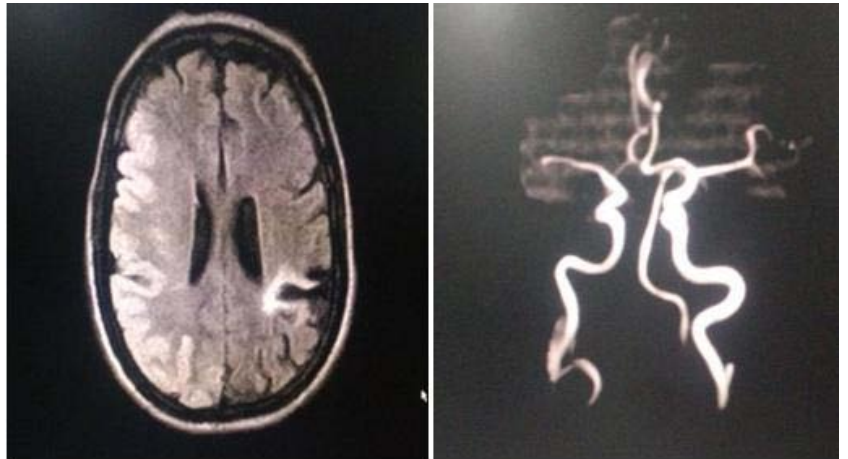

Figure 2: MRI Flair image and MRI angiography.

What does the investigation suggest-?

MRI- Infarct (100\%) - ACA (15\%), MCA (50\%), PCA (10\%), Vertebro-basilar (25\%)

MRI angiography- Normal (50\%), Abnormal (50\%)

Carotid Doppler (critical narrowing) - Normal (60\%), Abnormal $(40 \%)$

Echocardiography- Thrombus in $2 \%$ only (Table 2 )

Atherosclerosis risk factors - Hypertension (40\%), Diabetes (55\%), dyslipidemia (30\%), Carotid intima media thickness $>0.9 \mathrm{~mm}$ (20\%), smoking (15\%) Presence of hypertension was there in $40 \%$ of cases (mean blood pressure 160/90 mm Hg) but these cases were previously hypertensive (156/90 mm Hg mean blood pressure during last one year). The difference was not significant during the last one year and at the time of the stroke. Long standing blood pressure is a risk factor atherosclerosis but precipitating acute stroke without significant rise from previous mean value remains uncertain (Table 2) $[11-14]$.

Sympathetic activity - Resting pulse rate was within normal limits, so there was no overt increase in sympathetic activity (Table 1). High base line sympathetic activity (80\% SSR Spikes) (Figure 4) was present. Directly increased sympathetic activity preserves circulation and oxygen supply to vital organs including brain [15-17], therefore direct effect of increased sympathetic activity can't precipitate stroke. On the contrary increased sympathetic activity increases oxygen 


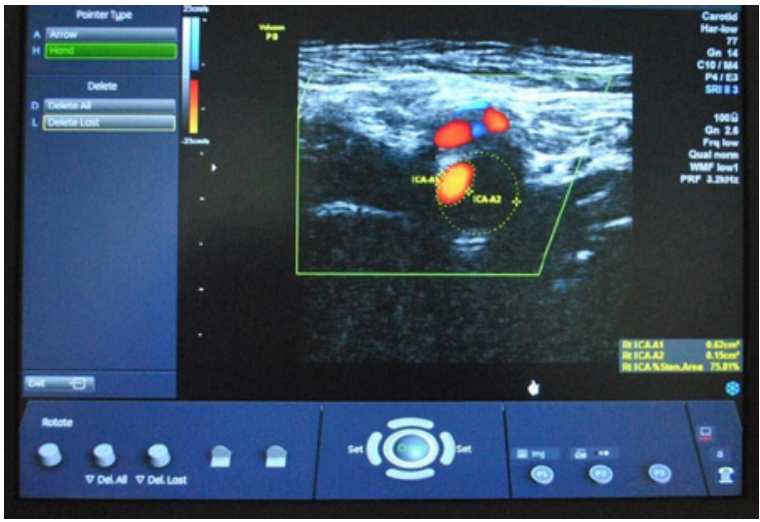

Figure 3: Color Doppler left ICA -axial view (76\% narrowing).

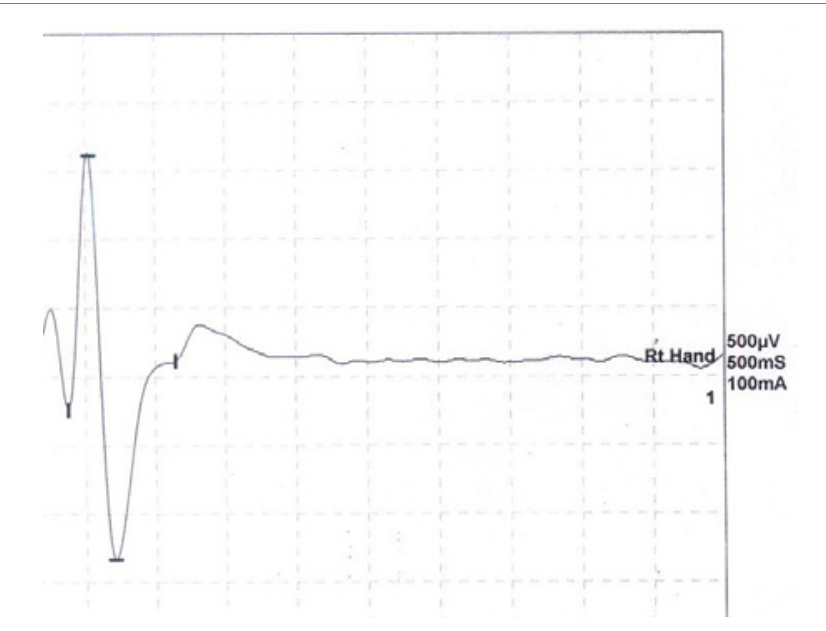

Figure 4: Sympathetic skin response.

demand of the tissues [18].

After going through investigations, it was found that there is a mismatch i.e. infarct $100 \%$ and abnormal flow maximum up to $50 \%$. Even a normal person coming for routine check- up has $75 \%$ (critical) narrowing in ICA. The similar degree of critical blockage becomes significant, in the same person or another person when it produces injury to brain?

Critical narrowing (> 70\%) is mainly atherosclerotic reduces blood and oxygen flow to brain. Atherosclerosis is a chronic process; chronicity always gives a chance to body to adapt to reduce blood flow. Absence of chronic symptoms/preceding TIA (transient ischemic attack) in the maximum number of cases (preceding TIA only 7\%) (Table 1); and acute appearance of stroke gives rise to the question of precipitating factor in the same narrowed vessel i.e. in the same vessel diameter one day the person is normal and develops stroke another day. How does the critical narrowing become even more critical?

There is no clear answer to such questions as to why stroke occurred in $50 \%$ nearly normal or normal cerebral circulation. It seems that in $40 \%-50 \%$ of cases despite sufficient blood flow and oxygen supply cell injury occurred. We have to trace the role of oxygen after reaching to the cell. Oxygen takes part in aerobic respiration/ cellular metabolism and generation of ATP. Therefore, the possible

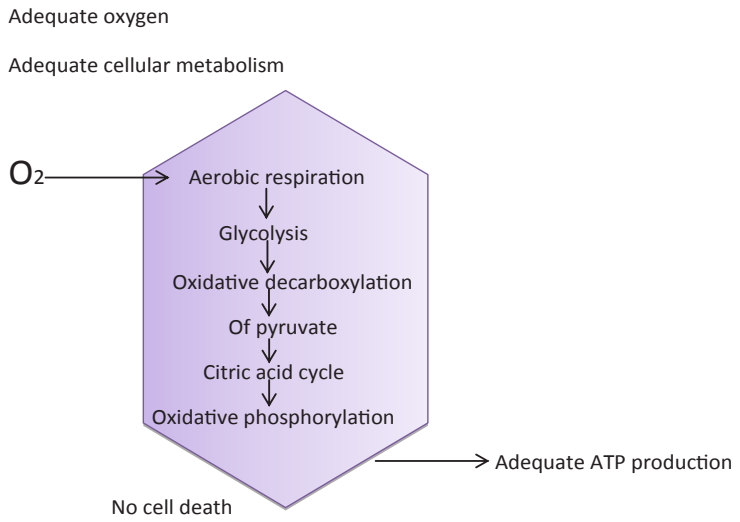

Figure 5: Normal cellular metabolism.

Inadequate oxygen (acute thromboembolic occlusion) (50\%)

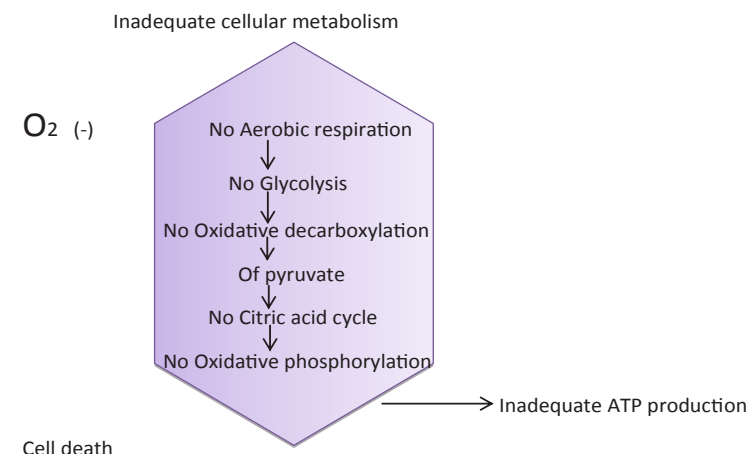

Cell death

Figure 6: Absent cellular metabolism.

mechanism may be there in cellular metabolism.

For normal cell functioning in brain, cells require glucose and oxygen and oxygen utilizing activity of cell i.e. activity sufficient to generate ATP through aerobic respiration or cellular metabolism. Cellular metabolism includes glycolysis, oxidative decarboxylation, citric acid cycle and oxidative phosphorylation to produce ATP (Adenosine tri phosphate) $[19,20]$ (Figure 5). Rate of cellular metabolism/ATP generation is in turn decided by basal metabolic rate (BMR) [14]. BMR is decided by hypothalamus according to external environmental temperature [21]. BMR is the minimum cell activity to produce ATP required for it's survival in a particular season.

Normally, the rate of metabolism (BMR/ basal metabolic rate) is set in a particular season (i.e. BMR increases in winter and decreases in summer season); cells function well, produces sufficient ATP, and no cell death occurs. Transformation in BMR from one season to other season occurs slowly so that body cells could adjust easily. Cell death can occur due to sudden unavailability of oxygen (Figure 6) or, a sudden change in BMR/ATP demand may not be tolerated/met quickly at cellular level. This happens in a person non-acclimatized to a particular environmental temperature /old age; sudden increase in metabolic requirement (winter to extreme winter, winter to spring, summer to autumn, summer to extreme summer), increased sympathetic activity/drugs/fever/dehydration/Stress or some unknown factor? There is unavailability of ATP (speed at which ATP is generated may not be sufficient) and despite availability of oxygen 


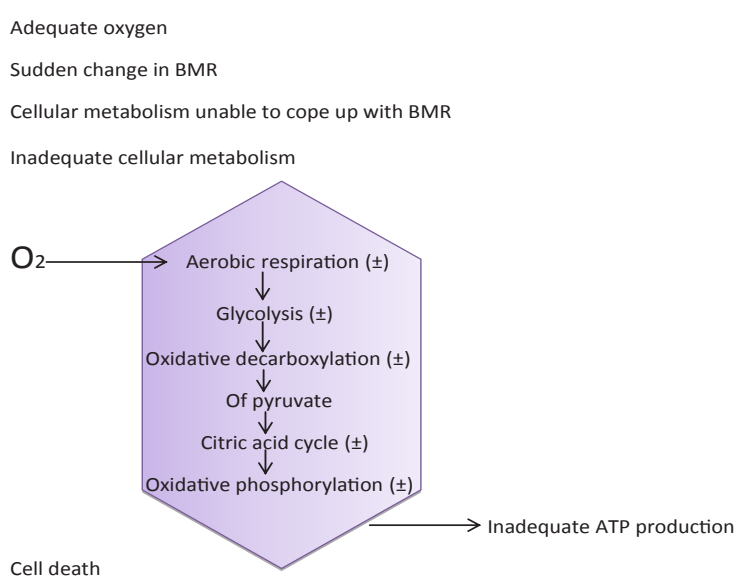

gure 7: Impaired cellular metabolism. $\mathrm{O}_{2}=$ Oxygen

and glucose, disproportion occurs between demand and availability of ATP leading to cell death (Figure 7). of:

We can explain the condition in a person who is hungry because

1. Sudden removal of food (sudden unavailability of oxygen i.e. acute occlusion by thrombus)

2. If the amount of food is gradually reduced over a number of years, the person is well adjusted to this amount of food (critical narrowing/atherosclerosis) and consumes food slowly

3. A person is having a normal amount of food, consumes food at a normal pace (normal cerebral circulation)

In situation 2 and 3 if the person is asked to consume the food very quickly (e.g.in one minute instead of ten minutes) he/she will face hunger. These situations explain why critical narrowing becomes more critical suddenly, and stroke occurs in a normal cerebral circulation (normal oxygen flow) when asked to generate ATP at a very fast speed.

\section{Possible Clinical Implications}

Besides restoring blood/ oxygen supply metabolic correction must be sought to prevent cell death in brain. In winter/ extreme winter metabolism may be boosted up by using coffee/spices/drugs and conversely in summer season.

\section{Acknowledgement}

Bharat Saxena (coordinator), Swati Gaurav (computer assistance).

\section{References}

1. Amre Nouh, Jessica Remke and Sean Ruland. Ischemic posterior circulation stroke: A review of Anatomy, Clinical presentations, Diagnosis and current management. Front Neurol.2014; 5: 30.

2. Béjot $Y$, Delpont B, Giroud M. Rising Stroke Incidence in Young Adults: More
Epidemiological Evidence, More Questions to Be Answered. J Am Heart Assoc. 2016; 5

3. https://doi.org/10.1161/JAHA.116.003661.

4. Feigin VL, Forouzanfar $\mathrm{MH}$, Krishnamurthi $\mathrm{R}$, Mensah GA, Connor $\mathrm{M}$ Bennett DA, et al. Global Burden of Diseases, Injuries, and Risk Factors Study 2010 (GBD 2010) and the GBD Stroke Experts Group. Global and regional burden of stroke during 1990-2010: findings from the Global Burden of Disease Study 2010. Lancet. 2014; 383: 245-254.

5. Johnston SC, Mendis S, Mathers CD. Global variation in stroke burden and mortality: estimates from monitoring, surveillance, and modelling. Lancet Neurol. 2009; 8: 345-354.

6. Bandera E, Botteri M, Minelli C, Sutton A, Abrams KR, Latronico N. Cerebral Blood Flow Threshold of Ischemic Penumbra and Infarct Core in Acute Ischemic Stroke. 2006; 37: 1334-1339.

7. Astrup J, Siesjö BK, Symon L. Thresholds in cerebral ischemia - the ischemic penumbra. Stroke. 1981; 12: 723-725.

8. Adams HP, Adams RJ, Brott T, del Zoppo GJ, Furlan A, Goldstein LB, et al. Guidelines for the early management of patients with ischemic stroke: a scientific statement from the Stroke Council of the American Stroke Association. Stroke. 2003; 34: 1056-1083.

9. Dennis I. Kasper, Stephen L. Hauser, j. Larry Jameson, Anthony S. Fauci, Dan I. Longo, joseph Loscalzo editors. Acute Ischemic Stroke. In text book of internal Medicine. Harrison's Principles of Internal Medicine. 19th ed. McGraw Hill: 2015; 2560- 2564.

10. Fulda S. Cross talk between cell death regulation and metabolism. Methods Enzymol. 2014; 542: 81-90.

11. http://dx.doi.org/10.1016/j.bbadis.2009.09.003.

12. https://doi.org/10.1161/01.CIR.0000131513.33892.5b.

13. The Expert Panel. Third Report of the National Cholesterol Education Program (NCEP) Expert Panel on Detection, Evaluation, and Treatment of High Blood Cholesterol in Adults (Adult Treatment Panel III). Final report. Circulation. 2002; 106: 3143-3421.

14. Castelli WP. Epidemiology of triglycerides: a view from Framingham. Am J Cardiol. 1992; 70: 3H-9H.

15. Sacks FM, Alaupovic P, Moye LA, Cole TG, Sussex B, Stampfer MJ, et al. VLDL, apolipoproteins $\mathrm{B}, \mathrm{CIII}$, and $\mathrm{E}$, and risk of recurrent coronary events in the Cholesterol and Recurrent Events (CARE) trial. Circulation. 2000; 102 : 1886-1892.

16. Heistad DD. Protection of the blood-brain barrier during acute and chronic hypertension. Fed Proc. 1984; 43: 205-209.

17. Mayhan WG, Werber AH, Heistad DD. Protection of cerebral vessels by sympathetic nerves and vascular hypertrophy. Circulation 1987; 75: I1071112.

18. Faraci FM, Mayhan WG, Werber AH, Heistad DD. Cerebral circulation: Effect of sympathetic nerves and protective mechanism during hypertention. Circ Res. 1987; 61: 102-106.

19. The Autonomic Nervous System - Autonomic effects on various organs of the body. In: Text book of medical physiology. Guyton \& Hall. Hall JE, Mario Vaz, AnuraKurpad, Tony raj editors, Elsevier; 2016; 831-833.

20. The cell and its Functions. In: Text book of medical physiology. Guyton \& Hall. Hall JE, Mario Vaz, Anura Kurpad, Tony raj editors, Elsevier 13th edition; 2016; 9-16.

21. https://en.wikipedia.org/wiki/cellular_respiration.
Austin J Cerebrovasc Dis \& Stroke - Volume 4 Issue 2 - 2017 ISSN : 2381-9103 | www.austinpublishing group.com Saxena et al. (C) All rights are reserved
Citation: Saxena T, Khichi G and Saxena M. Cell Death in Stroke: Role of Metabolism. Austin J Cerebrovasc Dis \& Stroke. 2017; 4(2): 1059 